\title{
Torin2 enhances the radiosensitivity of MCF-7 breast cancer cells by downregulating the mTOR signaling pathway and ATM phosphorylation
}

\author{
JIA LUO*, GUOCHENG PI*, HE XIAO, YUNFEI YE, QING LI, LIANHUA ZHAO, \\ HUAN HUANG, HONG LUO, QIN ZHANG, DONG WANG and GE WANG \\ Cancer Center of Daping Hospital and The Research Institute of Surgery, \\ The Third Military Medical University, Chongqing 400042, P.R. China
}

Received February 22, 2017; Accepted August 23, 2017

DOI: $10.3892 / \mathrm{mmr} .2017 .7848$

\begin{abstract}
Radiotherapy has an important role in the comprehensive treatment of breast cancer. However, the clinical outcome of adjuvant radiotherapy may be limited due to intrinsic radioresistance, it is necessary to explore efficient radiosensitization methods that improve the clinical outcome of patients undergoing radiotherapy. The present study aimed to investigate whether the novel mechanistic target of rapamycin (mTOR) inhibitor Torin2 enhances the radiosensitivity of MCF-7 breast cancer cells. A Cell Counting Kit- 8 (CCK-8) assay was performed to measure the effect of Torin2 on cell proliferation, while clonogenic assays were employed to determine the effect of Torin 2 in combination with radiation on the proliferation of MCF-7 cells. The effect of Torin2 and/or radiation on the cell cycle was analyzed using flow cytometry. Furthermore, the protein expression of components of the phosphatidylinositol 3-kinase/Akt/mTOR pathway, and the expression of proteins involved in DNA damage repair, was measured by western blot analysis. The results demonstrated that Torin 2 exhibited a higher potency in MCF-7 cells, while MDA-MB-231 cells were less sensitive to Torin2. Compared with irradiation alone, pretreatment with $20 \mathrm{nM}$ Torin2 followed by irradiation resulted in an increased level of $\gamma-\mathrm{H} 2 \mathrm{~A}$ histone family member X. Radiation induced the activation of the Akt/mTOR signaling pathway and upregulated the expression of phosphorylated (p)-Akt $\mathrm{At}^{473}$ and p-eukaryotic translation initiation factor $4 \mathrm{E}$ binding protein $1(4 \mathrm{EBP} 1)^{37 / 46}$. Notably,
\end{abstract}

Correspondence to: Professor Ge Wang, Cancer Center of Daping Hospital and The Research Institute of Surgery, The Third Military Medical University, 10 Changjiangzhi Road, Chongqing 400042, P.R. China

E-mail: wangge70@hotmail.com

*Contributed equally

Key words: breast cancer, MCF-7, mechanistic target of rapamycin kinase inhibitor, Torin2, radiosensitization pretreatment with Torin2 attenuated the radiation-induced activation of the Akt/mTOR signaling pathway. In addition, Torin2 partially blocked the repair of double-strand breaks induced by radiation by reducing the activation of ataxia telangiectasia-mutated, and sensitized MCF-7 cells to radiation. In conclusion, administration of Torin2 prior to irradiation enhanced the radiotherapeutic effect on breast cancer cells in vitro, and these results may provide a foundation for the rational use of combined therapy with irradiation and Torin2 for breast cancer in clinical practice.

\section{Introduction}

Breast cancer is a major health concern for women, and its incidence is rapidly increasing worldwide (1). The latest statistical data from the National Cancer Center reported that there were 268,600 new cases of breast cancer and 69,500 breast cancer-associated mortalities in females in China in 2015. In addition, breast cancer has the highest incidence among gynecological carcinomas (2). Radiotherapy has an important role in the comprehensive treatment of breast cancer, in addition to surgery, chemotherapy and endocrine therapy. The majority of patients diagnosed with early-stage breast cancer prefer conservative surgery followed by radiotherapy rather than mastectomy due to the low incidence of injury associated with the former treatment, which has become the primary strategy to cure breast cancer $(3,4)$. However, the clinical outcome of adjuvant radiotherapy may be limited due to intrinsic radioresistance that directly influences the prognosis and survival of patients. Therefore, it is necessary to investigate efficient radiosensitization methods that improve the clinical outcome of patients undergoing radiotherapy.

Recently, various studies have focused on targeted therapy, including the use of phosphatidylinositol 3-kinase (PI3K), mechanistic target of rapamycin (mTOR) and $\gamma$-secretase inhibitors in breast cancer (5-7). mTOR belongs to the family of serine/threonine protein kinases, and its two subtypes, mTORC1 and mTORC2, differ structurally (8). mTORC1 directly activates eukaryotic translation initiation factor $4 \mathrm{E}$ binding protein 1 (4EBP1) and ribosomal protein S6 kinase $\beta 1$ to facilitate translation, the cell cycle and angiogenesis, while mTORC2 induces the phosphorylation of Akt at serine 473 
to further activate the PI3K/Akt/mTOR pathway in a positive feedback manner.

mTOR, as one of the major downstream components of the $\mathrm{PI} 3 \mathrm{~K} / \mathrm{Akt}$ pathway, is functionally involved in protein translation and is involved in various biological processes, including tumor survival, proliferation and autophagy. mTOR is reported to be excessively activated in several tumor types as a result of hotspot mutations in phosphatidylinositol-4,5-bisphosphate 3-kinase catalytic subunit $\alpha$ (PIK3CA) (9-11). Therefore, mTOR has become a potential therapeutic target, particularly in breast cancer that harbors hotspot mutations in PIK3CA. Several clinical trials have demonstrated superior antitumor activity of different mTOR inhibitors in patients with breast cancer, and everolimus has been approved by the FDA for the treatment of advanced breast cancer (12).

Torin 2 is a novel, second-generation ATP-competitive mTOR inhibitor that demonstrates dual criteria as it suppresses mTORC1 and mTORC2, and also reduces the DNA damage repair response (13). Several preclinical studies have reported decreased proliferation and migration induced by Torin 2 in lung cancer, hepatocarcinoma, thyroid cancer and epithelial ovarian cancer (14-16). However, it is unclear whether Torin2 may enhance the radiosensitivity of cancer cell lines, particularly in breast cancer where PIK3CA mutations occur at a high frequency. Therefore, the present study aimed to investigate the effect of Torin 2 on the radiosensitivity of breast cancer cells and to explore the associated underlying mechanism of this synergy.

\section{Materials and methods}

Cell culture and inhibitor. MCF-7 and MDA-MB-231 human breast cancer cells were purchased from the American Type Culture Collection (ATCC; Manassas, VA, USA) and cultured in Dulbecco's modified Eagle's medium (DMEM; Hyclone; GE Healthcare Life Sciences, Logan, UT, USA) supplemented with $10 \%$ fetal bovine serum (Biological Industries Israel Beit Haemek Ltd., Beit Haemek, Israel), $100 \mu \mathrm{g} / \mathrm{ml}$ penicillin and $100 \mathrm{mg} / \mathrm{ml}$ streptomycin in a humidified incubator at $37^{\circ} \mathrm{C}$ with $5 \% \mathrm{CO}_{2}$. Exponentially growing cells were trypsinized for subculture or for further experiments. The selective mTOR inhibitor, Torin2 (cat. no. SML1224), was purchased from Sigma-Aldrich (Merck KGaA, Darmstadt, Germany).

Cell Counting Kit-8 (CCK-8) assay. Exponentially growing MCF-7 and MDA-MB-231 cells were seeded in $100 \mu \mathrm{l}$ media consist of DMEM with $10 \%$ FBS at a density of $5 \times 10^{3}$ cells/well in 96 -well plates and were incubated overnight at $37^{\circ} \mathrm{C}$. The following day, cells were treated with $0,25,50,100,200,400$ and $800 \mathrm{nM}$ Torin 2 for $48 \mathrm{~h}$ at $37^{\circ} \mathrm{C}$; wells containing cells and medium only were used as controls. Colorimetric readings were taken at $450 \mathrm{~nm}$ following incubation with CCK-8 (Bio-Rad Laboratories, Inc., Hercules, CA, USA) for $2 \mathrm{~h}$ at $37^{\circ} \mathrm{C}$. All assays were performed independently at least three times. The 20 and $50 \%$ inhibitory concentration $\left(\mathrm{IC}_{20}\right.$ and $\mathrm{IC}_{50}$ ) values for each cell line were calculated using the median-effect equation derived by Chou (17).

Clonogenic assays. MCF-7 cells were seeded at the density of $1 \times 10^{5}$ cells $/ \mathrm{ml}$ in $30-\mathrm{mm}$ dishes and allowed to adhere in the incubator overnight at $37^{\circ} \mathrm{C}$. Cells were subsequently pretreated with or without $20 \mathrm{nM}$ Torin2 (close to $\mathrm{IC}_{20}$ value) for $1 \mathrm{~h}$ prior to irradiation at $0-10 \mathrm{~Gy} \leq 1 \mathrm{~min}$. Cells were incubated for a further $24 \mathrm{~h}$ at $37^{\circ} \mathrm{C}$ and trypsinized to plate in 60-mm dishes, with $3 \times 10^{3}$ cells per dish, for a period of 2 weeks. The colonies that formed were stained with $0.1 \%$ crystal violet (Beyotime Institute of Biotechnology, Haimen, China) at room temperature for $2 \mathrm{~h}$, and colonies with $>50$ cells were counted using Quantity One software version 4.4.0 (Bio-Rad Laboratories, Inc.). A linear-quadratic model was used to evaluate their radiosensitivity (18).

Flow cytometry analysis. MCF-7 cells at the density of $1 \times 10^{5}$ cells $/ \mathrm{ml}$ were seeded in $60-\mathrm{mm}$ dishes allowed to adhere overnight at $37^{\circ} \mathrm{C}$ and were treated with or without Torin2 at a concentration of $20 \mathrm{nM}$ for $1 \mathrm{~h}$ at $37^{\circ} \mathrm{C}$ prior to irradiation with X-rays at 2 or $4 \mathrm{~Gy} \leq 30 \mathrm{sec}$. Cells were subsequently washed twice with PBS and suspended with pre-cooled $70 \%$ alcohol for fixing overnight. Following digestion with $100 \mu \mathrm{g} / \mathrm{ml}$ RNaseA at $37^{\circ} \mathrm{C}$ for $30 \mathrm{~min}, 50 \mu \mathrm{g} / \mathrm{ml}$ propidium iodide $(550825$; BD Pharmingen; BD Biosciences, San Diego, CA, USA) was added to the cells for $30 \mathrm{~min}$ at room temperature and they were kept protected from light. The fluorescence intensity of each cell was measured using a MoFlo XDP flow cytometer with Kaluza Analysis Software version 1.3 (Beckman Coulter, Inc., Brea, CA, USA).

Western blot analysis. MCF-7 cells were treated with 0 , 200 and $400 \mathrm{nM}$ Torin 2 for $2 \mathrm{~h}$, or $200 \mathrm{nM}$ Torin 2 for 0,2 , 4 and $8 \mathrm{~h}$ at $37^{\circ} \mathrm{C}$. In another experiment, MCF-7 cells were treated with or without Torin2 at a concentration of $20 \mathrm{nM}$ for $1 \mathrm{~h}$ at room temperature prior to irradiation with X-rays at $0-10 \mathrm{~Gy} \leq 1 \mathrm{~min}$. Cells were lysed in radioimmunoprecipitation assay lysis buffer (Beyotime Institute of Biotechnology) on ice for $10 \mathrm{~min} 48 \mathrm{~h}$ after irradiation. Cell lysates were centrifuged at $12,000 \times \mathrm{g}$ at $4^{\circ} \mathrm{C}$ for $15 \mathrm{~min}$ and the supernatants were collected. Protein concentrations were measured in the supernatant using a Pierce BCA Protein assay kit (Thermo Fisher Scientific, Inc., Waltham, MA, USA). A total of $50 \mu \mathrm{g}$ protein from each sample was separated by $10 \%$ SDS-PAGE and transferred onto a polyvinylidene fluoride membrane (EMD Millipore, Billerica, MA, USA), which was followed by blocking with $5 \%$ bovine serum albumin (Bio-sharp, Hefei, China) at $37^{\circ} \mathrm{C}$ for $1 \mathrm{~h}$, incubated overnight at room temperature with the indicated primary antibodies followed by incubation with corresponding secondary antibodies for $2 \mathrm{~h}$ at room temperature and detection using Pierce ECL Western Blotting Substrate (Thermo Fisher Scientific, Inc.). $\beta$-tubulin was used as the loading control. The signal intensity with background correction was quantified using Quantity One software version 4.4.0 (Bio-Rad Laboratories, Inc.). The following antibodies were obtained from Cell Signaling Technology, Inc. (Danvers, MA, USA): Phosphorylated (p)-Akt ${ }^{473}$ (cat. no. 9271, 1:1,000), Akt (cat. no. 9272, 1:1,000), P-4EBP1 ${ }^{37 / 46}$ (cat. no. 2855, 1:1,000), 4EBP1 (cat. no. 9452, 1:1,000), $\gamma$-H2A histone family member X (H2AX; cat. no. 9718, 1:1,000), p-ataxia telangiectasia-mutated (ATM; cat. no. 5883, 1:1,000), p-ATR serine/threonine kinase (ATR; cat. no. 2853, 1:1,000), $\beta$-tubulin (cat. no. 2146, 1:5,000), horseradish peroxidase (HRP)-conjugated goat anti-rabbit (cat. no. 7074, 1:5,000). 
A

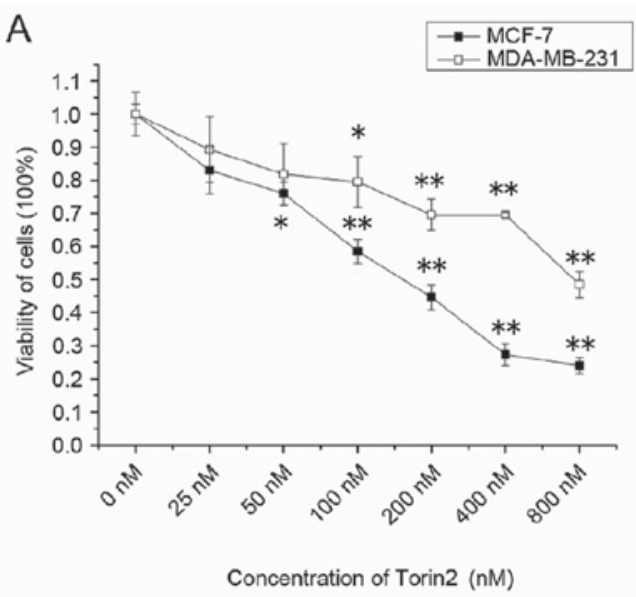

C

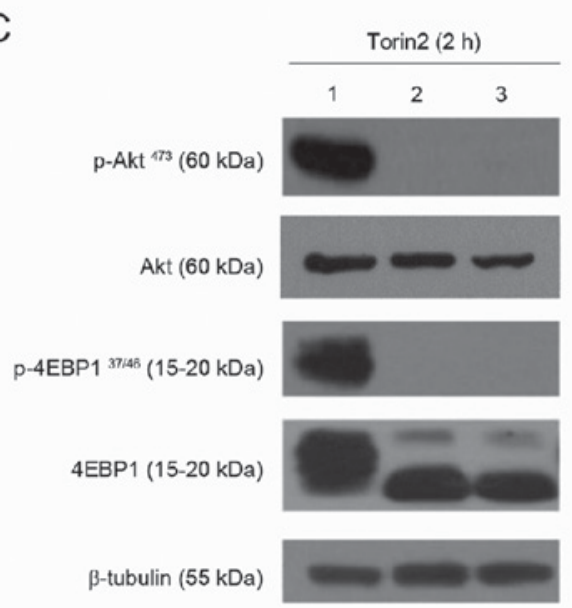

B

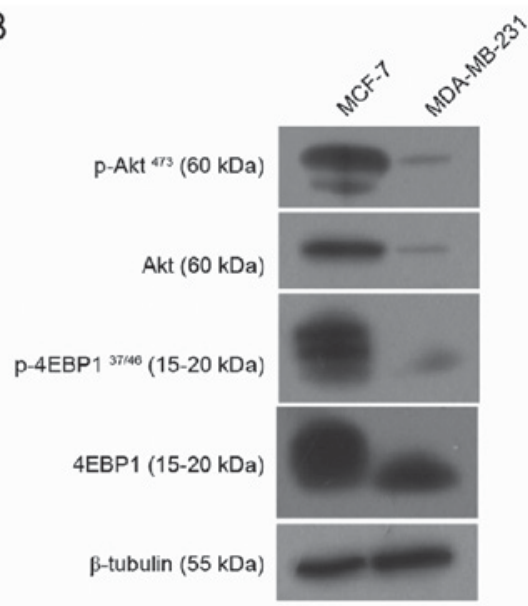

D

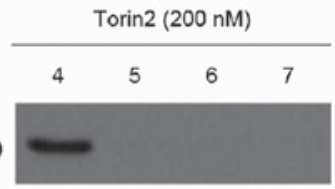

Akt (60 kDa)

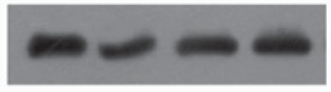

p-4EBP1 ${ }^{37 / 4}(15-20 \mathrm{kDa})$

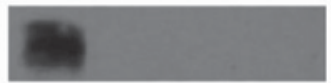

4EBP1 (15-20 kDa)

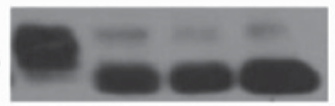

$\beta$-tubulin (55 kDa)

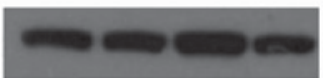

Figure 1. Torin2 suppresses cell viability and mTOR signaling pathway in breast cancer cells. (A) Viability assay for MCF-7 and MDA-MB-231 cell lines treated with 0-800 nM Torin 2 for $48 \mathrm{~h}$. (B) Protein expression of major components of the mTOR signaling pathway under routine culture conditions in MCF-7 and MDA-MB-231 cell lines. (C) MCF-7 cells were exposed to 0, 200 and $400 \mathrm{nM}$ Torin 2 for $2 \mathrm{~h}$ and western blotting was performed. Lanes 1, 2 and 3 present results for cells treated with 0,200 and $400 \mathrm{nM}$ Torin2, respectively. (D) MCF-7 cells were exposed to $200 \mathrm{nM}$ Torin2 for $0,2,4$ and $8 \mathrm{~h}$ and western blotting was performed. Lanes, 4, 5, 6 and 7 present results for cells treated with Torin 2 for $0,2,4$ and $8 \mathrm{~h}$, respectively. $\beta$-tubulin was used as a loading control. ${ }^{*} \mathrm{P}<0.05$ and ${ }^{* *} \mathrm{P}<0.01$ vs. $0 \mathrm{nM}$ group. mTOR, mechanistic target of rapamycin; p, phosphorylated; 4EBP1, eukaryotic translation initiation factor $4 \mathrm{E}$ binding protein 1.

Statistical analysis. Data are presented as the mean \pm standard deviation. Each experiment was repeated at least three times. Significance was determined using two-tailed unpaired Student's t-tests. All figures and statistical analysis were performed with Origin version 8.0 (OriginLab, Northampton, MA, USA). P<0.05 was considered to indicate a statistically significant difference.

\section{Results}

Torin2 inhibits cell proliferation by downregulating the mTOR signaling pathway. CCK- 8 assay results demonstrated that the viability of MCF-7 and MDA-MB-231 cells was significantly decreased by Torin2 in a dose-dependent manner (Fig. 1A). However, Torin2 was more potent in MCF-7 cells, with $\mathrm{IC}_{20}$ and $\mathrm{IC}_{50}$ values of 32.1 and $163.4 \mathrm{nM}$, respectively, compared with MDA-MB-231 cells, which had $\mathrm{IC}_{20}$ and $\mathrm{IC}_{50}$ values of 83.9 and $1012.8 \mathrm{nM}$, respectively. In order to validate the drug-targeted effect, western blot analysis was performed to evaluate the protein expression of the major components of the Akt/mTOR pathway. Consistent with the effects of Torin 2 on cell growth, the basal expression of $\mathrm{p}$-Akt and P-4EBP1 were elevated in MCF-7 cells compared with MDA-MB-231 cells (Fig. 1B). As demonstrated in Fig. 1C, $\mathrm{p}-\mathrm{Akt}^{473}$ and $\mathrm{P}-4 \mathrm{EBP} 1^{37 / 46}$ expression was abolished when MCF-7 cells were treated with 200 or $400 \mathrm{nM}$ Torin 2 for $2 \mathrm{~h}$. Furthermore, $\mathrm{p}-\mathrm{Akt}^{473}$ and $\mathrm{P}-4 \mathrm{EBP} 1^{37 / 46}$ expression was inhibited in MCF-7 cells by treatment with $200 \mathrm{nM}$ Torin2 for up to $8 \mathrm{~h}$ (Fig. 1D). As 4EBP1 and Akt are direct substrates of the enzymes mTORC1 and mTORC2, respectively, these results indicate that Torin 2 may reduce the viability of MCF-7 cells by diminishing mTOR activity, therefore, MCF-7 cells were selected for subsequent experiments.

Torin2 enhances the radiosensitivity of MCF-7 cells. Colony formation assay results demonstrated that treatment with $20 \mathrm{nM}$ Torin 2 prior to irradiation sensitized cells to radiation compared with cells treated with radiation alone (Fig. 2A). The parameters of $\alpha$ and $\beta$ calculated using the linear-quadratic model were $0.264 \pm 0.029 \mathrm{~Gy}^{-1}$ and $0.029 \pm 0.005 \mathrm{~Gy}^{-2}$, respectively, for cells treated with a combination of radiation and Torin2, and 0.057 $\pm 0.016 \mathrm{~Gy}^{-1}$ and $0.031 \pm 0.002 \mathrm{~Gy}^{-2}$, respectively, for those treated with radiation alone (Fig. 2B). These 
A IR dose (Gy)

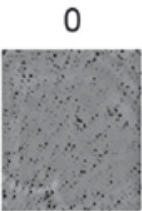

2 4 6
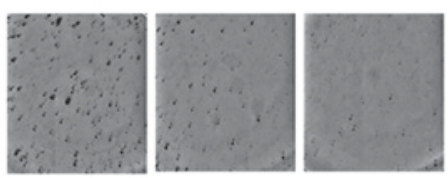
8 10

IR
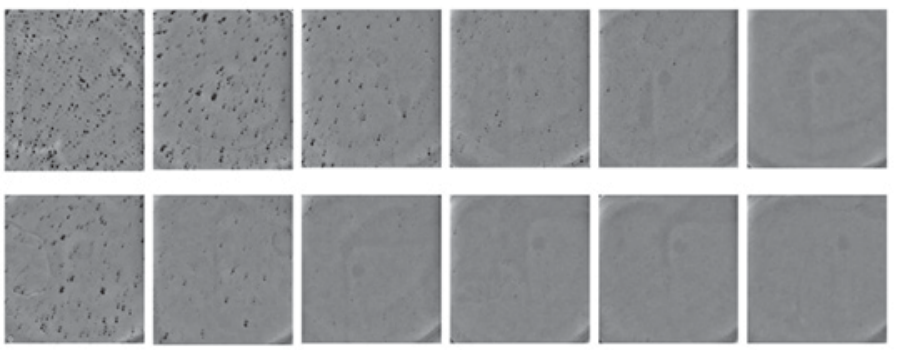

Torin2 + IR

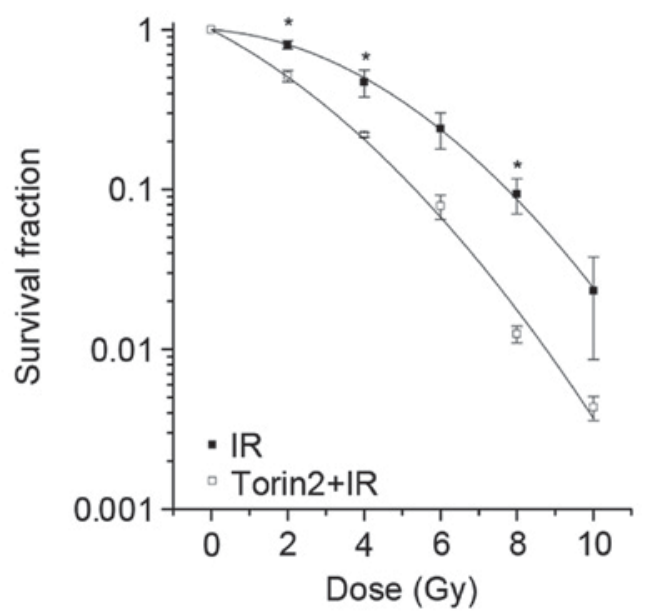

Figure 2. Torin2 enhances the radiosensitivity of MCF-7 cells. (A) Representative images of results for the colony formation assay. (B) Quantified results for clonogenic survival assays. Data are presented as the mean \pm standard deviation of three replicates. The results indicate that pretreatment with $20 \mathrm{nM}$ Torin2 for $1 \mathrm{~h}$ prior to irradiation resulted in radiation dose-dependent inhibition of MCF-7 cells. ${ }^{*} \mathrm{P}<0.05$ vs. Torin $2+$ IR group at same radiation dose. IR, irradiation.

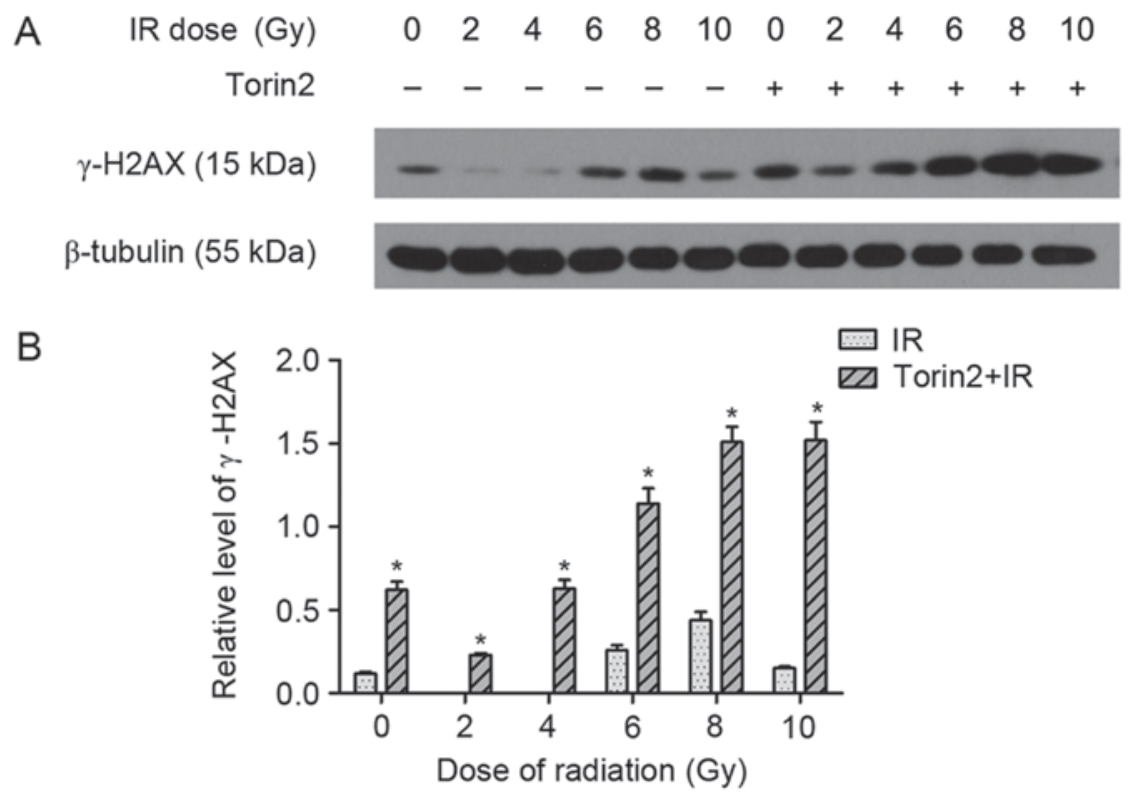

Figure 3. Torin2 induces $\gamma$-H2AX expression in MCF-7 cells. (A) Representative western blot bands for MCF-7 cells treated with $20 \mathrm{nM}$ Torin2 followed by 0-10 Gy radiation. (B) Quantification of the relative protein expression of $\gamma$-H2AX by densitometric analysis. "P<0.05 vs. IR alone at same radiation dose. H2AX, H2A histone family member X; IR, irradiation.

data indicate that pharmacological inhibition of mTOR using Torin2 enhanced the radiosensitivity of MCF-7 cells in vitro.

Torin2 increases the level of $\gamma-H 2 A X$ induced by radiation. To investigate the potential mechanism of enhanced radiosensitivity induced by Torin2, the protein expression of $\mathrm{p}-\mathrm{H} 2 \mathrm{AX}$, which is a well-established indicator of DNA double-strand breaks (DSBs) induced by radiation, was evaluated in MCF-7 cells treated with or without $20 \mathrm{nM}$ Torin 2 followed by an increasing dose of radiation. Induction of $\gamma$ - $\mathrm{H} 2 \mathrm{AX}$ expression by irradiation in MCF-7 cells was dose dependent, and the expression was markedly elevated at 6 and 8 Gy (Fig. 3A). 
A
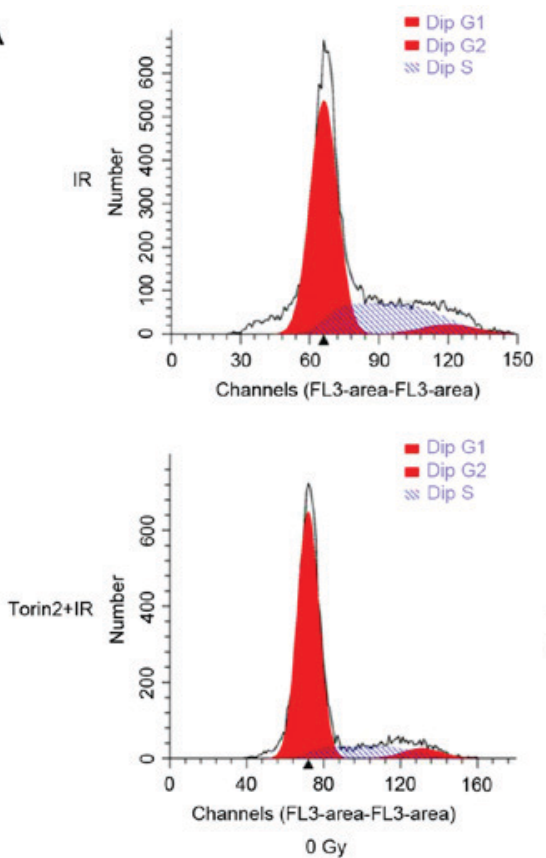

B

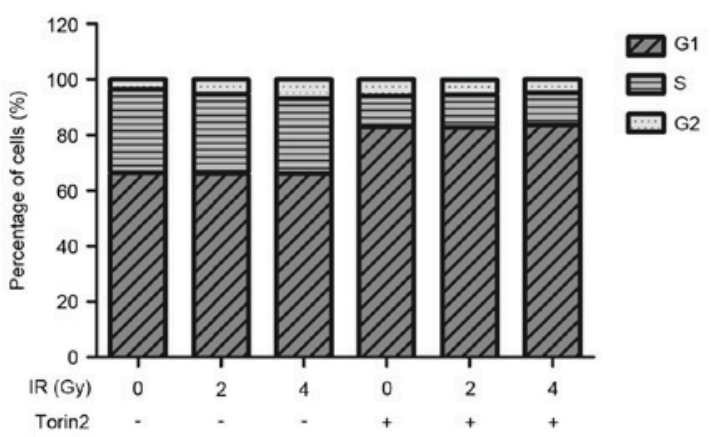

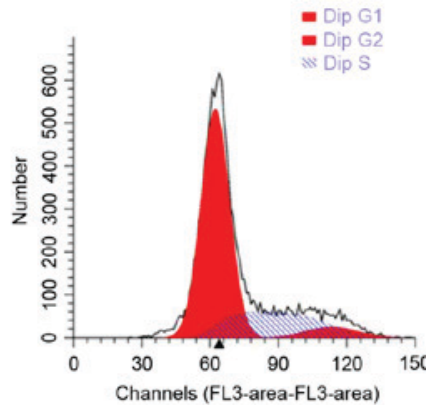
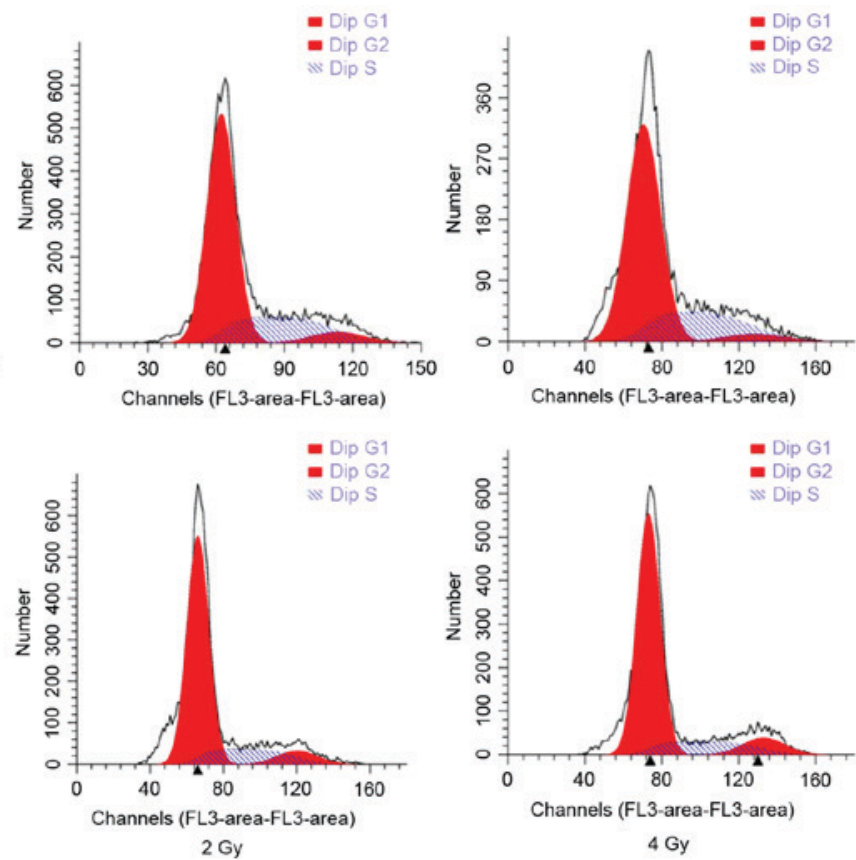

C

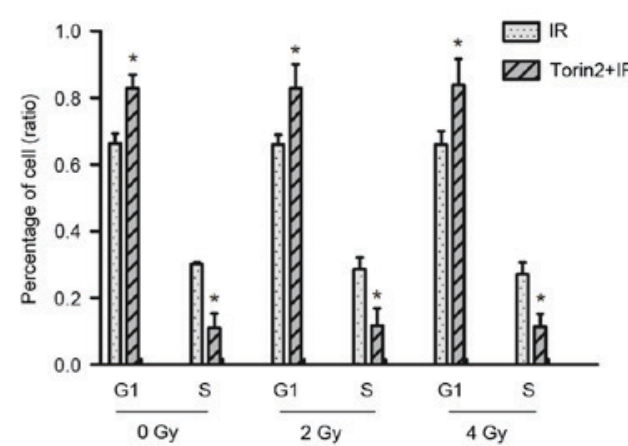

Figure 4. G1/S phase arrest is induced by Torin2 alone in MCF-7 cells but is not further influenced by combination with irradiation. (A) Cell cycle analysis of MCF-7 cells treated with 0-10 Gy radiation with or without pretreatment with $20 \mathrm{nM}$ Torin2. (B) Percentage of cells in each group in each phase of the cell cycle. (C) Percentage ratios for each cell cycle phase and statistical analysis. ${ }^{*}<0.05$ vs. IR alone at same cell cycle phase.

However, compared with the induced expression of $\gamma$-H2AX in MCF-7 cells treated with radiation alone, expression was further induced in cells that were pretreated with Torin2 (fold change, $4.34 \pm 0.56$ and $10.02 \pm 1.00$ at 6 and $10 \mathrm{~Gy}$, respectively; Fig. 3B). These results indicate that Torin 2 may enhance the lethal effect of radiation on MCF-7 cells by increasing DNA damage.

Torin2 induces cell cycle arrest in the G1/S phase. Flow cytometry was performed to investigate the effect of Torin2 on cell cycle arrest (Fig. 4A). The G1 phase cell population increased by $16.57 \%$, whereas the $\mathrm{S}$ phase population significantly decreased by $19.17 \%$, in MCF-7 cells treated with Torin2 alone compared with control cells without Torin2 or irradiation treatment (Fig. 4B). The percentage of cells in G1 and S phases were significantly increased and decreased, respectively, compared with cells treated with radiation alone at different radiation doses (Fig. 4C). However, the combination of Torin 2 and irradiation at 2 and $4 \mathrm{~Gy}$ did not enhance alterations in cell cycle distribution in MCF-7 cells compared with cells treated with Torin 2 alone.
Torin2 downregulates the expression of the mTOR signaling pathway. A previous study reported that hyperactivity of the Akt/mTOR axis may confer radioresistance to glioblastoma cell lines (19). In the present study, radiation alone induced marginally elevated p-Akt expression in MCF-7 cells at low doses, and markedly increased p-Akt expression at higher doses (Fig. 5). P-4EBP1 was induced at low radiation doses and decreased when the dose was increased between 6 and $10 \mathrm{~Gy}$. Sustained inhibition of p-Akt and almost complete downregulation of P-4EBP1 was observed in MCF-7 cells pretreated with Torin 2 . These results, combined with those for $\gamma$-H2AX expression, indicate that Torin 2 may enhance the radiosensitivity of MCF-7 cells through inhibition of $\mathrm{Akt} / \mathrm{mTOR}$ signaling and subsequent impairment of DNA repair machinery.

Torin 2 sensitizes breast cancer cells to radiation by attenuating DNA repair mechanisms. To confirm whether the attenuation of DNA repair mechanisms induced by Torin 2 contributes to radiosensitization of MCF-7 cells, the present study analyzed the protein expression of p-ATM and p-ATR (Fig. 6). The 


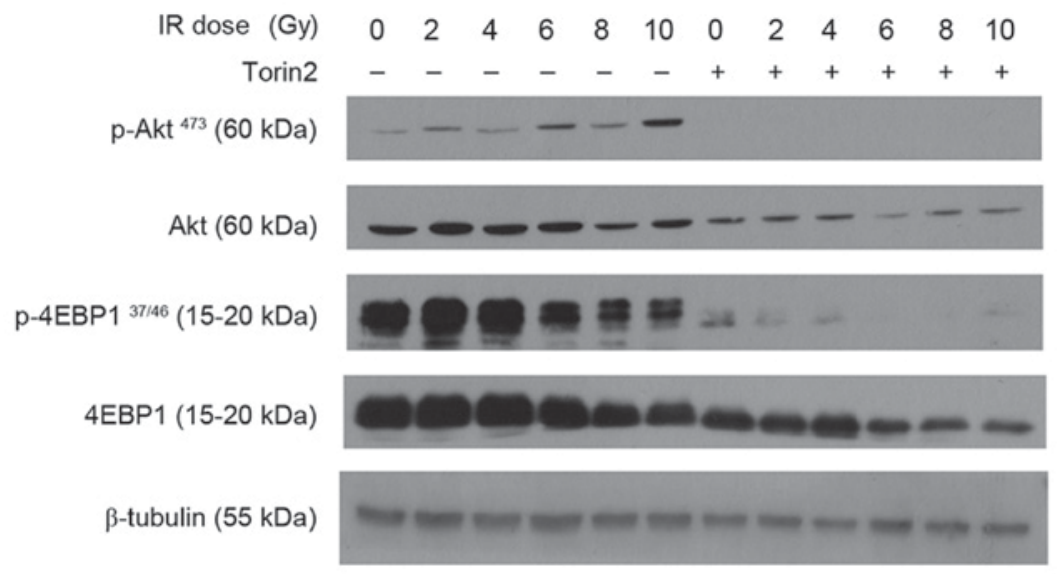

Figure 5. Representative western blot results for MCF-7 cells treated with $20 \mathrm{nM}$ Torin 2 followed by $0-10$ Gy radiation. The results indicate that p-Akt ${ }^{473}$ and P-4EBP ${ }^{37 / 46}$ were upregulated by irradiation and almost completely suppressed by Torin 2 pretreatment. p, phosphorylated; 4EBP1, eukaryotic translation initiation factor $4 \mathrm{E}$ binding protein 1 ; IR, irradiation.

$$
\begin{array}{r}
\text { IR dose (Gy) } \\
\text { Torin2 } \\
\text { p-ATR }(300 \mathrm{kDa}) \\
\text { ATR }(300 \mathrm{kDa}) \\
\text { p-ATM }(370 \mathrm{kDa}) \\
\text { ATM }(370 \mathrm{kDa}) \\
\text { B-tubulin }(55 \mathrm{kDa})
\end{array}
$$
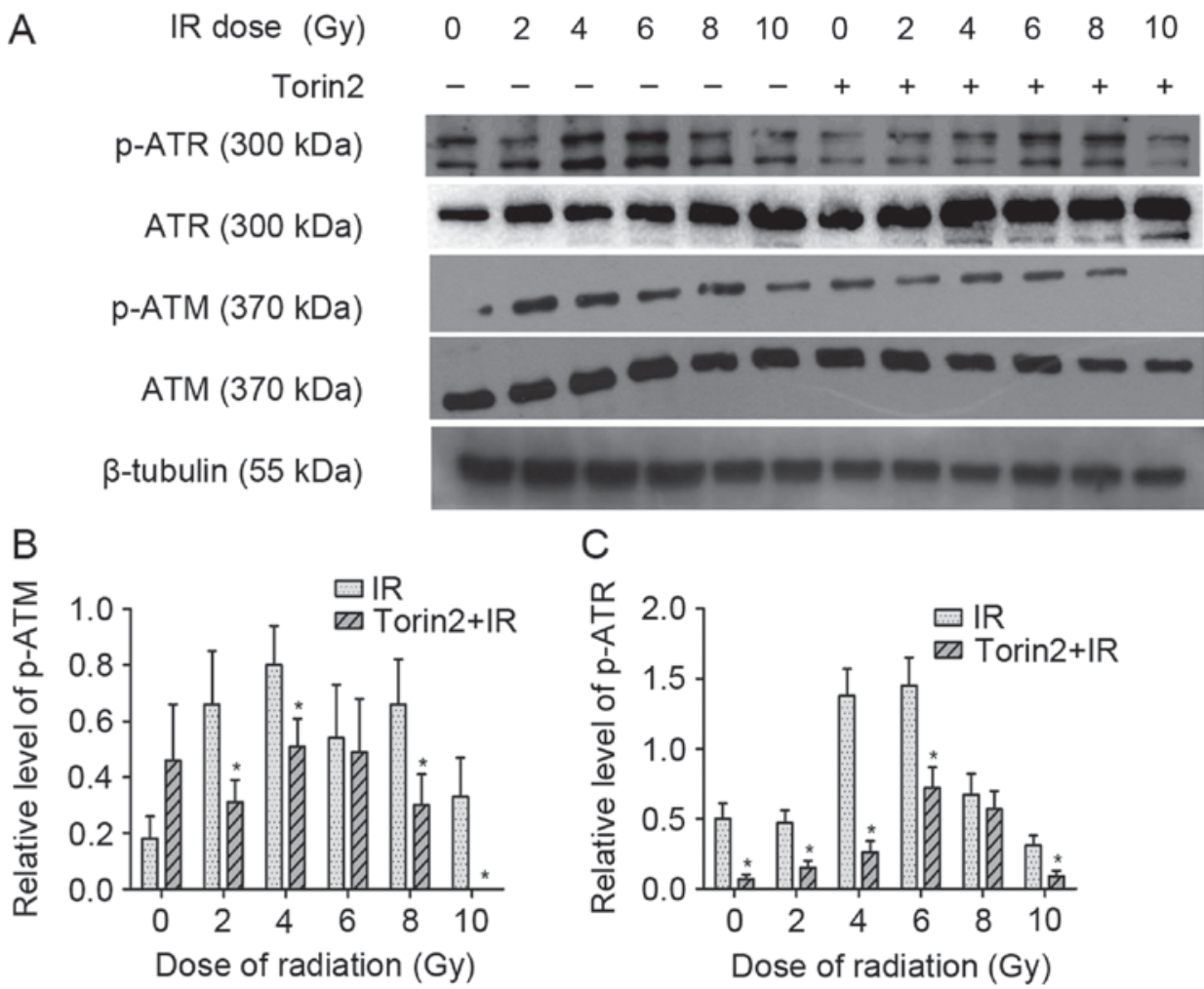

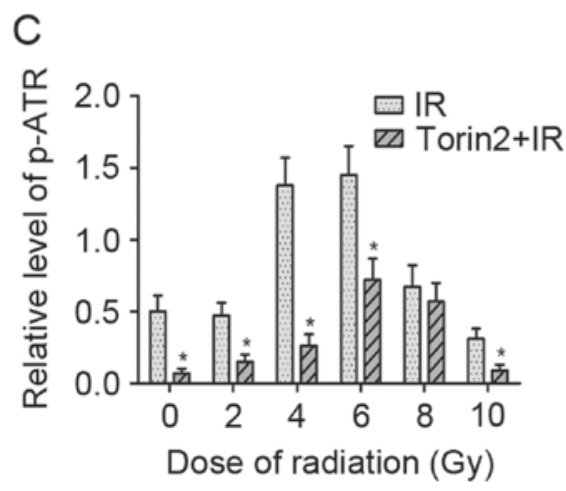

Figure 6. Torin2 decreases the expression of p-ATM and p-ATR induced by irradiation alone. (A) Representative western blot results for MCF-7 cells treated with $20 \mathrm{nM}$ Torin2 followed by $0-10 \mathrm{~Gy}$ radiation. (B) Quantification of the relative expression of (B) p-ATM and (C) p-ATR by densitometric analysis. "P<0.05 vs. IR alone at same radiation dose. p, phosphorylated; ATM, ataxia telangiectasia-mutated; ATR, ATR serine/threonine kinase; IR, irradiation.

results demonstrated that irradiation alone markedly enhanced the expression of p-ATR. Although MCF-7 cells treated with radiation alone and those pretreated with Torin 2 exhibited a similar expression of ATR and ATM, the expression of p-ATM and p-ATR in Torin2-treated MCF-7 cells was significantly diminished compared with the expression observed in MCF-7 cells treated with radiation alone at the majority of radiation doses. These results demonstrated that the effect of Torin2 on the radiosensitization of MCF-7 cells may be partially attributed to impaired DSB repair due to inactivation of the Akt/mTOR signaling pathway.

\section{Discussion}

Excessive activation of the PI3K/Akt/mTOR pathway was reported in $30-50 \%$ cases of breast cancer, which may be attributed to mutations in the oncogene PIK3CA (20-22). Liu et al (23) reported that the mTOR inhibitor INK128 radiosensitized breast cancer cell lines. Consistent with the results of their study, the results of the present study demonstrated that the novel mTOR inhibitor Torin 2 inhibited the proliferation and enhanced the radiosensitivity of MCF-7 cells. Torin2 also markedly inhibited the phosphorylation of 4EBP1 and 
Akt, which are direct substrates of mTORC1 and mTORC2, respectively, indicating that the activities of $\mathrm{mTORC} 1$ and mTORC 2 may be inhibited by Torin 2 . Unlike other traditional mTOR inhibitors that inhibit only mTORC1, Torin 2 inhibits both isoforms. To the best of our knowledge, the present study is the first to report that the novel mTOR inhibitor Torin2 inhibited the proliferation and enhanced the radiosensitivity of breast cancer cells. Furthermore, growth inhibition assay results also demonstrated that MDA-MB-231 cells are more resistant Torin2 than MCF-7 cells. MCF-7 cells belong to the luminal subtype of breast cancer and are primarily characterized by a high frequency of PIK3CA mutations, while MDA-MB-231 cells belong to the basal-like subtype and exhibit the epithelial-mesenchymal transition phenotype (24). Therefore, PI3K/Akt/mTOR is a growth-dependent pathway in MCF-7 cells but not in MDA-MB-231 cells.

Research on genomics and proteomics has revealed that the mechanisms of radioresistance in cancer are complex, and involve the tumor microenvironment and genomic and epigenetic alterations (25). Aberrant activation of oncogenic signaling pathways such as the PI3K/Akt/mTOR pathway has an important role in radioresistance. The mechanisms of radioresistance due to activation of the PI3K/Akt $/ \mathrm{mTOR}$ pathway include intrinsic radioresistance, tumor cell proliferation and hypoxia (26). Activated mTOR induced by irradiation has been observed in several cancer types, including lung and prostate cancer $(8,27)$. In the present study, upregulated mTOR activity, reflected by phosphorylation status, was also observed in MCF-7 cells treated with radiation alone. However, mTOR activity was suppressed in MCF-7 cells treated with Torin2 prior to irradiation. Therefore, the ability of Torin 2 to enhance the radiosensitivity of MCF-7 cells may be partially attributed to reduced mTOR activity, which reduces the response to DNA damage repair.

To further investigate the potential mechanisms of radiosensitization by Torin2, flow cytometry analysis was performed to evaluate the cell cycle progression in MCF-7 cells with or without Torin 2 pretreatment. The results demonstrated an increase in the G1 phase cell population, which was accompanied by a reduced proportion of cells in the $\mathrm{S}$ phase. Consistent with these results, previous studies have reported that Akt inhibitors downregulated the expression of cyclin D1, which led to G1/S arrest in various cancer cells. It is well established that, compared with cells in the $\mathrm{S}$ phase, those in the G1 phase are more sensitive to irradiation (28-30). Therefore, radiosensitization may be partially attributed to altered cell cycle distribution induced by Torin 2 .

Cell membrane deconstruction and DNA damage induced by irradiation, which enhance apoptosis, have important roles in the anticancer effect of irradiation. Irradiation leads to DNA single-strand breaks (SSBs) and DSBs, and the accumulation of DSBs exerts lethal effects. ATR primarily participates in SSB repair, whereas the ATM gene and DNA-dependent protein kinase $\mathrm{C}$ are involved in the repair of DSBs through homologous recombination and non-homologous end joining, respectively (31-33). In the present study, increased $\gamma-\mathrm{H} 2 \mathrm{AX}$ expression combined with reduced p-ATR and p-ATM in MCF-7 cells treated with Torin2 and irradiation was observed. These results indicate that Torin2-enhanced radiosensitivity of MCF-7 cells may be partially mediated by the suppression of ATR and ATM activity, and subsequent diminished DNA repair capacity.

In conclusion, the present study demonstrated that Torin2 inhibited the growth of MCF-7 cells and enhanced their radiosensitivity. The enhanced radiosensitivity of MCF-7 cells by Torin 2 may be attributed to three factors: mTOR activity was blocked by Torin2, which may lead to decreased radioresistance; Torin 2 induced G1/S arrest and inhibited cell proliferation, and subsequently improved the radiosensitivity; and Torin 2 enhanced the radiosensitivity of MCF-7 cells by reducing the capacity for DNA damage repair via inhibition of ATM and ATR activity. However, a single breast cancer cell line was employed to obtain these results in the present study, no animal model was used to validate the results in vivo and association analysis with certain genomic alterations was not performed. Therefore, further detailed investigation of the radiosensitization mechanism of Torin 2 is required. However, the results of the present study may provide a theoretical foundation to rationally utilize a combination of irradiation and Torin2 therapy for breast cancer in clinical practice.

\section{Acknowledgements}

The present study was supported by grants from the National Natural Science Foundation of China (grant no. 81572959) and the Chinese Society of Clinic Oncology (grant no. Y-MX2015-041). The authors thank Medjaden Bioscience, Ltd. (Hong Kong, SAR, P.R. China) for providing an English language service.

\section{References}

1. Langlands FE, Horgan K, Dodwell DD and Smith L: Breast cancer subtypes: Response to radiotherapy and potential radiosensitisation. Br J Radiol 86: 20120601, 2013

2. Chen W, Zheng R, Baade PD, Zhang S4, Zeng H, Bray F, Jemal A, $\mathrm{Yu}$ XQ and He J: Cancer statistics in China, 2015. CA Cancer J Clin 66: 115-132, 2016.

3. Fisher CM and Rabinovitch R: Frontiers in radiotherapy for early-stage invasive breast cancer. J Clin Oncol 32: 2894-2901, 2014.

4. Lee HC, Kim SH, Suh YJ, Chung MJ, Kang DG, Choi HJ and Lee JH: A prospective cohort study on postoperative radiotherapy with TomoDirect using simultaneous integrated boost technique in early breast cancer. Radiat Oncol 9: 244, 2014.

5. Di Cosimo S, Bianchi GV, Bregni G and de Braud F: Prognosis of women with early breast cancer and PIK3CA mutations. Breast 24: 283-284, 2015.

6. Guerrero-Zotano A,MayerIA and ArteagaCL:PI3K/AKT/mTOR: Role in breast cancer progression, drug resistance and treatment. Cancer Metastasis Rev 35: 515-524, 2016.

7. Mamaeva V, Niemi R, Beck M, Özliseli E, Desai D, Landor S, Gronroos T, Kronqvist P, Pettersen IK, McCormack E, et al: Inhibiting notch activity in breast cancer stem cells by glucose functionalized nanoparticles carrying gamma-secretase Inhibitors. Mol Ther 24: 926-936, 2016.

8. Chang L, Graham PH, Ni J, Hao J, Bucci J, Cozzi PJ and Li Y: Targeting PI3K/Akt/mTOR signaling pathway in the treatment of prostate cancer radioresistance. Crit Rev Oncol Hematol 96: 507-517, 2015.

9. García-Carracedo D, Villaronga MÁ, Álvarez-Teijeiro S, Hermida-Prado F, Santamaría I, Allonca E, Suárez-Fernández L, Gonzalez MV, Balbín M, Astudillo A, et al: Impact of $\mathrm{PI} 3 \mathrm{~K} / \mathrm{AKT} / \mathrm{mTOR}$ pathway activation on the prognosis of patients with head and neck squamous cell carcinomas. Oncotarget 7: 29780-29793, 2016.

10. Loi S, Michiels S, Baselga J, Bartlett JM, Singhal SK, Sabine VS, Sims AH, Sahmoud T, Dixon JM, Piccart MJ and Sotiriou C: PIK3CA genotype and a PIK3CA mutation-related gene signature and response to everolimus and letrozole in estrogen receptor positive breast cancer. PLoS One 8: e53292, 2013. 
11. Wang L, Hu H, Pan Y, Wang R, Li Y, Shen L, Yu Y, Li H, Cai D, Sun Y and Chen H: PIK3CA mutations frequently coexist with EGFR/KRAS mutations in non-small cell lung cancer and suggest poor prognosis in EGFR/KRAS wildtype subgroup. PLOS One 9: e88291, 2014.

12. Moulder SL, Rivera E, Ensor J, Gonzalez-Angulo AM, Cristofanilli M, Murray JL, Booser D, Giordano SH, Brewster A, Moore J, et al: Phase I trial of escalating doses of weekly everolimus (RAD001) in combination with docetaxel for the treatment of metastatic breast cancer (MBC). J Clin Oncol 118: 2378-2384, 2012.

13. Liu Q, Xu C, Kirubakaran S, Zhang X, Hur W, Liu Y, Kwiatkowski NP, Wang J, Westover KD, Gao P, et al: Characterization of Torin2, an ATP-competitive inhibitor of mTOR, ATM, and ATR. Cancer Res 73: 2574-2586, 2013.

14. Hussain AR, Al-Romaizan M, Ahmed M, Thangavel S, Al-Dayel F, Beg S, Uddin S, Siraj AK and Al-Kuraya KS: Dual targeting of mTOR activity with Torin 2 potentiates anticancer effects of cisplatin in epithelial ovarian cancer. Mol Med 21: 466-478, 2015

15. Sadowski SM, Boufraqech M, Zhang L, Mehta A, Kapur P, Zhang Y, Li Z, Shen M and Kebebew E: Torin2 targets dysregulated pathways in anaplastic thyroid cancer and inhibits tumor growth and metastasis. Oncotarget 6: 18038-18049, 2015.

16. Wang C, Wang X, Su Z, Fei H, Liu X and Pan Q: The nove mTOR inhibitor Torin-2 induces autophagy and downregulates the expression of UHRF1 to suppress hepatocarcinoma cell growth. Oncol Rep 34: 1708-1716, 2015.

17. Chou TC: Drug combination studies and their synergy quantification using the Chou-Talalay method. Cancer Res 70: 440-446, 2010.

18. Franken NA, Rodermond HM, Stap J, Haveman J and van Bree C: Clonogenic assay of cells in vitro. Nat Protoc 1: 2315-2319, 2006.

19. Mukherjee B, Tomimatsu N, Amancherla K, Camacho CV, Pichamoorthy $\mathrm{N}$ and Burma S: The Dual PI3K/mTOR inhibitor NVP-BEZ235 is a potent inhibitor of ATM- and DNA-PKCs-mediated DNA damage responses. Neoplasia 14: 34-43, 2012.

20. Cejalvo JM, Perez-Fidalgo JA, Ribas G, Burgués O, Mongort C, Alonso E, Ibarrola-Villava M, Bermejo B, Martínez MT, Cervantes A and Lluch A: Clinical implications of routine genomic mutation sequencing in PIK3CA/AKT1 and KRAS/NRAS/BRAF in metastatic breast cancer. Breast Cancer Res Treat 160: 69-77, 2016.

21. Basho RK, Gagliato DM, Ueno NT, Wathoo C, Chen H, Shariati M, Wei C, Alvarez RH, Moulder SL, Sahin AA, et al: Clinical outcomes based on multigene profiling in metastatic breast cancer patients. Oncotarget 7: 76362-76373, 2016.
22. Azizi Tabesh G, Izadi P, Fereidooni F, Emami Razavi AN and Tavakkoly Bazzaz J: The high frequency of PIK3CA mutations in Iranian breast cancer patients. Cancer Invest 35: 36-42, 2017.

23. Liu ZG, Tang J, Chen Z, Zhang H, Wang H, Yang J and Zhang H: The novel mTORC1/2 dual inhibitor INK 128 enhances radiosensitivity of breast cancer cell line MCF-7. Int J Oncol 49: 1039-1045, 2016

24. Kao J, Salari K, Bocanegra M, Choi YL, Girard L, Gandhi J, Kwei KA, Hernandez-Boussard T, Wang P, Gazdar AF, et al: Molecular profiling of breast cancer cell lines defines relevant tumor models and provides a resource for cancer gene discovery. PLoS One 4: e6146, 2009.

25. Yahyanejad S, Theys J and Vooijs M: Targeting Notch to overcome radiation resistance. Oncotarget 7: 7610-7628, 2016.

26. Kim BM, Hong Y, Lee S, Liu P, Lim JH, Lee YH, Lee TH, Chang KT and Hong Y: Therapeutic implications for overcoming radiation resistance in cancer therapy. Int J Mol Sci 16: 26880-26913, 2015.

27. Heavey S, O'Byrne KJ and Gately K: Strategies for co-targeting the PI3K/AKT/mTOR pathway in NSCLC. Cancer Treat Rev 40: 445-456, 2014

28. Shimura T: Acquired radioresistance of cancer and the AKT/GSK3ß/cyclin D1 overexpression cycle. J Radiat Res 52: 539-544, 2011.

29. Shimura T, Kakuda S, Ochiai Y, Nakagawa H, Kuwahara Y, Takai Y, Kobayashi J, Komatsu K and Fukumoto M: Acquired radioresistance of human tumor cells by DNA-PK/AKT/GSK3beta-mediated cyclin D1 overexpression. Oncogene 29: 4826-4837, 2010

30. Shimura T: Targeting the AKT/cyclin D1 pathway to overcome intrinsic and acquired radioresistance of tumors of effective radiotherapy. Int J Radiat Biol 93: 381-385, 2017.

31. Javvadi P, Makino H, Das AK, Lin YF, Chen DJ, Chen BP and Nirodi CS: Threonine 2609 phosphorylation of the DNA-dependent protein kinase is a critical prerequisite for epidermal growth factor receptor-mediated radiation resistance. Mol Cancer Res 10: 1359-1368, 2012.

32. Bunimovich YL, Nair-Gill E, Riedinger M, McCracken MN, Cheng D, McLaughlin J, Radu CG and Witte ON: Deoxycytidine kinase augments ATM-Mediated DNA repair and contributes to radiation resistance. PLoS One 9: e104125, 2014

33. Guy JB, Rancoule C, Méry B, Espenel S, Wozny AS, Simonet S, Vallard A, Alphonse G, Ardail D, Rodriguez-Lafrasse C and Magné N: Radiosensitivity and/or radioresistance of head and neck cancers: Biological angle. Bull Cancer 103: 41-47, 2016. 